\title{
Assessment of Prevalence and Risk Factors of Dry Eye Disease among Study Group
}

\author{
Madhavi Chevuturu ${ }^{\circledR}$ \\ Professor and HOD, Department of Ophthalmology, ESIC Medical College, Hyderabad, Telangana, India.
}

\section{Abstract}

Background: Dry eye is a multifactorial disease of the tears and ocular surface that results in symptoms of discomfort, visual disturbance. The present study was conducted to assess prevalence and risk factors of dry eye diseases among the study group. Subjects and Methods: The present study was conducted from February 2018 to July 2018 on 184 patients of both genders visiting the Department of Ophthalmology Mediciti institute of medical sciences with eye complaints. Slit-lamp biomicroscopy with a cobalt blue filter was used to investigate the tear film layer, and the interval from the last blink to the appearance of the first random dry spot on the cornea was noted. Schirmer's test was performed. Whatman filter paper no 41 was placed in the lower fornix at the lateral one-third of the lower lid margin. Results: Age groups 40-50 years had 52, 50-60 years had 98 and 60-70 years had 34 patients. There were 110 males and 74 females. The difference was significant $(\mathrm{P}<0.05)$. 64 (58.1\%) males and $40(54 \%)$ had a dry eye disease. The prevalence found to be $61.9 \%$. The severity of DED was mild in $25 \%$, moderate in $46 \%$ and severe in $29 \%$. The difference was significant $(\mathrm{P}<0.05)$. Risk factors of DED were steroid use in $14 \%$, smoking in $56 \%$, alcoholism in $24 \%$, computer job in $78 \%$, systemic allergy in $4 \%$, ocular allergy in $32 \%$, contact lens use in $17 \%$ and previous ocular surgery in $7 \%$. The difference was significant $(\mathrm{P}<0.05)$. Conclusion: The author found that the prevalence rate of dry eyes was $61.9 \%$. Risk factors of DED were steroid use, smoking, alcoholism, computer job, systemic allergy, ocular allergy, contact lens use and previous ocular surgery.

Keywords: Dry eyes, smoking, alcoholism

Corresponding Author: Madhavi Chevuturu, Professor and HOD, Department of Ophthalmology, ESIC Medical College, Hyderabad, Telangana, India.

E-mail: drmadhavi28@gmail.com

Received: 11 May 2020

Revised: 13 June 2020

Accepted: 26 June 2020

Published: 06 October 2020

\section{Introduction}

The term dry-eye syndrome is defined as "a multifactorial disease of the tears and ocular surface that results in symptoms of discomfort, visual disturbance, and tear film instability with potential damage to the ocular surface. ${ }^{[1]}$ It is accompanied by increased osmolarity of the tear film and inflammation of the ocular surface". Dry eye refers to disorders of the tear film due to reduced tear production and/or excessive tear evaporation associated with symptoms of ocular discomfort. ${ }^{[2]}$

The prevalence of dry eye disease (DED) is greatly influenced by geographic location, climatic conditions, and lifestyle of the people and ranges from $5 \%$ to $35 \%{ }^{[3]}$ However, different definitions of dry eyes are employed in various epidemiological studies which may not be standardized, and limited data exist on the potential effect of race or ethnicity on dry eye prevalence. There is a need to expand epidemiological studies to more geographic regions using standardized questionnaires and uniform diagnostic criteria. ${ }^{[4]}$
Very few studies have described the epidemiology of DED from the Indian subcontinent. Risk factors for two or more signs included age and self-report of arthritis. A large study used questionnaires to investigate the prevalence of DES in Canada in all age groups. In the 13,517 returned questionnaires (55\% aged $21-50$ years, $60.7 \%$ were women), $28.7 \%$ of respondents reported DES. Those reporting severe DES were predominantly women, with a ratio of $46: 1 .{ }^{[5]}$

Patients with dry eye often complain of pain, heaviness, foreign body sensation, redness, photo phobia and reflex watering due to corneal irritation. Because the tear film in dry eye patients is unstable and incapable of maintaining the protective qualities that are necessary for its structure and function, patients may complain of symptoms of dry eye in the presence or absence of signs of the disease. ${ }^{[6]}$ The present study was conducted to assess prevalence and risk factors of dry eye diseases among study groups. 


\section{Subjects and Methods}

The present study was conducted from February 2018 to July 2018 on 184 patients of both genders visiting the Department of Ophthalmology Mediciti institute of medical sciences with eye complaints. Ethical approval was obtained from the institute before the study. All patients were informed regarding the study and written consent was obtained.

General information such as name, age etc. was recorded. Symptoms of dry eye such as dryness, grittiness, burning, stickiness, heaviness, itching and watering were recorded. Slitlamp biomicroscopy with a cobalt blue filter was used to investigate the tear film layer, and the interval from the last blink to the appearance of the first random dry spot on the cornea was noted. Schirmer's test was performed. Whatman filter paper no 41 was placed in the lower fornix at the lateral one-third of the lower lid margin. The extent of the wetting of the strip was measured after $5 \mathrm{~min}$. Less than $5.5 \mathrm{~mm}$ of wetting was diagnosed with severe dry eye. Results thus obtained were subjected to statistical analysis. A P-value of less than 0.05 was considered significant.

\section{Results}

\begin{tabular}{|lll|}
\hline \multicolumn{2}{|l|}{ Table 1: Demographic profile of patients } & \\
\hline Age groups (Years) & Number & P values \\
\hline $40-50$ & 52 & 0.05 \\
\hline $50-60$ & 98 & \\
$60-70$ & 34 & \\
Gender & & \\
Male & 110 & 0.02 \\
\hline Female & 74 & \\
\hline
\end{tabular}

[Table 1] shows that age groups 40-50 years had 52, 50-60 years had 98 and $60-70$ years had 34 patients. There were 110 males and 74 females. The difference was significant $(\mathrm{P}<$ $0.05)$.

[Table 2] shows that 64 (58.1\%) males and 40 (54\%) had a dry eye disease. The prevalence found to be $61.9 \%$.

[Table 3] shows that the severity of DED was mild in $25 \%$, moderate in $46 \%$ and severe in $29 \%$. The difference was significant $(\mathrm{P}<0.05)$.

[Table 4, Figure 1] shows that risk factors of DED were steroid use in $14 \%$, smoking in $56 \%$, alcoholism in $24 \%$, computer job in $78 \%$, systemic allergy in $4 \%$, ocular allergy in $32 \%$, contact lens use in $17 \%$ and previous ocular surgery in $7 \%$. The difference was significant $(\mathrm{P}<0.05)$.

\begin{tabular}{|lll|}
\hline Table 2: Prevalence of DED & \\
\hline Total & Number & DED \\
Male & 110 & 64 \\
Female & 74 & 40 \\
\hline
\end{tabular}

Table 3: Severity of DED

\begin{tabular}{lll}
\hline Severity & Percentage & P-value \\
Mild & $25 \%$ & 0.02 \\
Moderate & $46 \%$ & \\
Severe & $29 \%$ & \\
\hline
\end{tabular}

Table 4: Risk factors of DED

\begin{tabular}{lll}
\hline Variables & Percentage & P-value \\
\hline Steroid use & $14 \%$ & 0.01 \\
\hline Smoking & $56 \%$ & \\
Alcoholism & $24 \%$ & \\
Computer job & $78 \%$ & \\
\hline Systemic allergy & $4 \%$ & \\
Ocular allergy & $32 \%$ & \\
\hline $\begin{array}{l}\text { Contact lens use } \\
\text { Previous ocular }\end{array}$ & $17 \%$ & \\
surgery & & \\
\hline
\end{tabular}

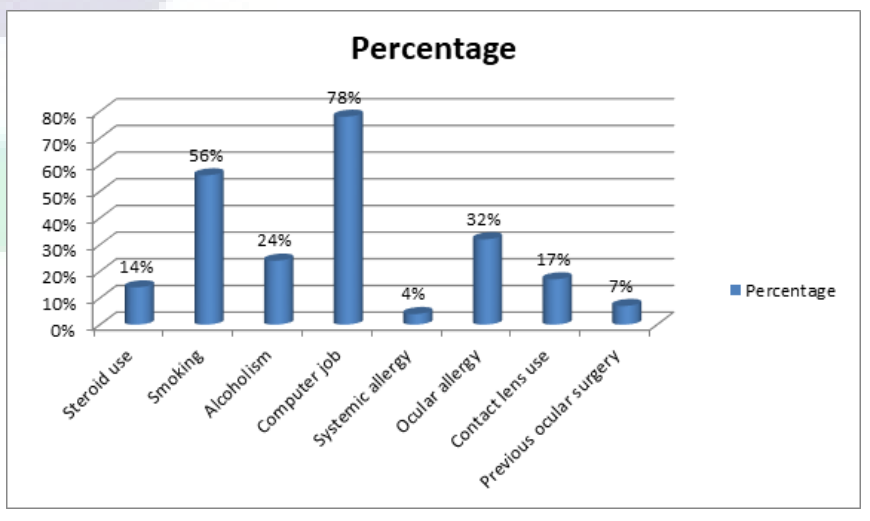

Figure 1: Risk factors of DED

\section{Discussion}

DED is one of the most prevalent ophthalmic disorders and may hurt the quality of life. ${ }^{[7]}$ In addition to causing various disabling symptoms, it may also compromise the results of the corneal, cataract, and refractive surgical procedures. Several objective tests have been developed to diagnose and grade the severity of DED. ${ }^{[8]}$ However, these tests show poor repeatability, significant inter observer variability and 
correlate poorly with the patient symptoms as well as the quality of life. Different patient-reported outcome (PRO) questionnaires have been developed to assess the quality of life in patients with DED, which act as a useful tool to aid in the screening, monitoring, and management of DED. ${ }^{[9]}$ The present study was conducted to assess prevalence and risk factors of dry eye diseases among the study group.

We found that age groups 40-50 years had 52, 50-60 years had 98 and 60-70 years had 34 patients. There were 110 males and 74 females. $64(58.1 \%)$ males and $40(54 \%)$ had a dry eye disease. The prevalence found to be $61.9 \%$. Chen et al, ${ }^{[10]}$ found that Of 6657 consecutive outpatients aged above 20 years, symptomatic dry eye present in 635 (9.54\%) subjects. 532 (7.99\%) out of those 635 subjects were clinically diagnosed as defined DED who combined with positive signs. The prevalence was significantly higher in patients aged 3150 years $(p<0.005)$ and significantly lower in the age group of over 70 years $(\mathrm{p}<0.001)$, which demonstrated an inverted Ushaped relationship, which females $(10.41 \%)$ was significantly higher than compared to males $(5.21 \%)$ ). Overexposure to visual display terminal (VDT) was a major risk factor for DED among young men and women (56.2\%). High and low risk of occupational exposure to adverse environments accounted for a large proportion, $31.2 \%$ and $20.9 \%$ respectively. Contact lenses use was closely associated with DED in young women, and the history of ocular surgeries might be another factor associated with DED in old people. 163 (43.9\%) of 371 female dry eye patients were associated with hormonal changes. The incidence of meibomian gland dysfunction related DED increased gradually with age. There were only $10(1.9 \%)$ dry eye patients were associated with Sjögren's syndrome and all of them were females.

We found that the severity of DED was mild in $25 \%$, moderate in $46 \%$ and severe in $29 \%$. Risk factors of DED were steroid use in $14 \%$, smoking in $56 \%$, alcoholism in $24 \%$, computer job in $78 \%$, systemic allergy in $4 \%$, ocular allergy in $32 \%$, contact lens use in $17 \%$ and previous ocular surgery in $7 \%$. Titiyal et al, ${ }^{[11]}$ in their study, a total of 15,625 patients were screened. The prevalence of DED was 32\% (5000/15625); 9.9\% (496/5000) had mild DED; 61.2\% (3060/5000) had moderate DED, and $28.9 \%(1444 / 5000)$ had severe DED. The age group of 21-40 years, male sex, urban region, and desk job were associated with an increased risk of DED. Hours of visual display terminal (VDT) usage significantly correlated with DED, and $89.98 \%$ of patients with 4 hours or more of VDT use had a severe dry eye. Cigarette smoking and contact lens usage had increased odds of developing severe DED. Objective tests were undertaken in 552 patients; of these, $81.3 \%$ (449/552) had severe DED.

Shah et al, ${ }^{[12]}$ found that the mean age of the study population was 58.6 years. The overall prevalence of dry eye was found to be $54.3 \%$. An association was found between dry eye prevalence and outdoor workers, participants working indoor using air conditioners, housewives, diabetics, patients who have undergone previous ocular surgery and those with meibomian gland dysfunction. Dry eye is a very common condition with a high prevalence among the elderly. We recommend the screening of all out-patients by TBUT, which is a simple test to perform and examination of lids for meibomian gland disease, which if present, can be treated. Further studies are needed to establish uniform diagnostic criteria for dry eye, which will help to get more concrete prevalence data, as well as its etiological factors.

Dry eyes are common eye complaints among all age groups. Careful assessment of risk factors may help prevent the occurrence of disease.

\section{Conclusion}

The author found that the prevalence rate of dry eyes was $61.9 \%$. Risk factors of DED were steroid use, smoking, alcoholism, computer job, systemic allergy, ocular allergy, contact lens use and previous ocular surgery.

\section{References}

1. Gayton J. Etiology, prevalence, and treatment of dry eye disease. Clin Ophthalmol. 2009;3:405-405. Available from: https://dx.doi.org/10.2147/opth.s5555.

2. Simpson TL, Situ P, Jones LW, Fonn D. Dry Eye Symptoms Assessed by Four Questionnaires. Optom Vis Sci. 2008;85(8):692-699. Available from: https://dx.doi.org/10. 1097/opx.0b013e318181ae36.

3. Lee AJ, Lee J, Saw SM, Gazzard G, Koh D, Widjaja D. Prevalence and risk factors associated with dry eye symptoms: A population based study in Indonesia. $\mathrm{Br} \mathrm{J}$ Ophthalmol. 2002;86(12):1347-51. Available from: https://doi.org/10. 1136/bjo.86.12.1347.

4. Baudouin C, Aragona P, Setten GV, Rolando M, Irkeç M, del Castillo JB, et al. Diagnosing the severity of dry eye: a clear and practical algorithm. $\mathrm{Br} \mathrm{J}$ Ophthalmol . 2014;98(9):1168-1176. Available from: https://dx.doi.org/10. 1136/bjophthalmol-2013-304619.

5. Schaumberg DA, Dana R, Buring JE, Sullivan DA. Prevalence of dry eye disease among US men: Estimates from the Physicians' Health Studies. Arch Ophthalmol. 2009;127:763771. Available from: https://doi.org/10.1001/archophthalmol. 2009.103.

6. Uchino M, Dogru M, Yagi Y, Goto E, Tomita M, Kon T, et al. The Features of Dry Eye Disease in a Japanese Elderly Population. Optom Vis Sci. 2006;83(11):797-802. Available from: https://dx.doi.org/10.1097/01.opx.0000232814.39651.fa.

7. Kaiserman I, Kaiserman N, Nakar S, Vinker S. Dry eye in diabetic patients. Am J Ophthalmol. 2005;139(3):498-503. Available from: https://dx.doi.org/10.1016/j.ajo.2004.10.022.

8. Han SB, Hyon JY, Woo SJ, Lee JJ, Kim TH, Kim KW. Prevalence of dry eye disease in an elderly Korean population. 
Arch Ophthalmol. 2011;129(5):633-641. Available from: https://doi.org/10.1001/archophthalmol.2011.78.

9. Galor A, Feuer W, Lee DJ, Florez H, Carter D, Pouyeh B, et al. Prevalence and Risk Factors of Dry Eye Syndrome in a United States Veterans Affairs Population. Am J Ophthalmol. 2011;152(3):377-384. Available from: https://dx.doi.org/10. 1016/j.ajo.2011.02.026.

10. Chen W, Li J, Zheng Q. Prevalence and risk factors of dry eye disease among a hospital-based population. Investig Ophthalmol Vis Sci. 2013;54(15):935-943.

11. Titiyal JS, Falera RC, Falera RC, Sharma V, Sharma N. Prevalence and risk factors of dry eye disease in North India: Ocular surface disease index-based cross-sectional hospital study. Indian J Ophthalmol. 2018;66(2):207-207. Available from: https://dx.doi.org/10.4103/ijo.IJO $698 \quad 17$.

12. Shah S, Jani H. Prevalence and associated factors of dry eye: Our experience in patients above 40 years of age at a
Tertiary Care Center. Oman J Ophthalmol. 2015;8(3):151-151. Available from: https://dx.doi.org/10.4103/0974-620x.169910.

Copyright: (C) the author(s), 2020. It is an open-access article distributed under the terms of the Creative Commons Attribution License (CC BY 4.0), which permits authors to retain ownership of the copyright for their content, and allow anyone to download, reuse, reprint, modify, distribute and/or copy the content as long as the original authors and source are cited.

How to cite this article: Chevuturu M. Assessment of Prevalence and Risk Factors of Dry Eye Disease among Study Group. Asian J. Med. Res. 2020;9(3):1-4.

DOI: dx.doi.org/10.47009/ajmr.2020.9.3.OT1

Source of Support: Nil, Conflict of Interest: None declared. 